\title{
The Analysis of Global Warming Patterns from 1970s to $2010 s$
}

\author{
Ali Cheshmehzangi ${ }^{1,2}$ \\ ${ }^{1}$ Department of Architecture and Built Environment, The University of Nottingham Ningbo China, Ningbo, China \\ ${ }^{2}$ Centre for Sustainable Energy Technologies, The University of Nottingham Ningbo China, Ningbo, China \\ Email: Ali.Cheshmehzangi@nottingham.edu.cn
}

How to cite this paper: Cheshmehzangi, A. (2020) The Analysis of Global Warming Patterns from 1970s to 2010s. Atmospheric and Climate Sciences, 10, 392-404.

https://doi.org/10.4236/acs.2020.103022

Received: May 6, 2020

Accepted: June 27, 2020

Published: July 1, 2020

Copyright $\odot 2020$ by author(s) and Scientific Research Publishing Inc. This work is licensed under the Creative Commons Attribution International License (CC BY 4.0).

http://creativecommons.org/licenses/by/4.0/

(c) (i) Open Access

\begin{abstract}
While global warming is only one part of climate change effects, it poses the highest risk to our habitats and ecologies. It is alarming that global warming has heightened in multiple locations and is intensified since the early 1970s. Since then, there are certain global warming patterns that could guide us with an overview of what mitigation and adaptation strategies should be developed in the future decades. There are certain regions affected more than another, and there are certain patterns with adverse effects on regions, sub-regions, and even continents. This study provides an insightful analysis of recent global warming patterns, those that are affecting us the most with regional climate change of different types, upsurge in frequency and intensity of natural disasters, and drastic impacts on our ecosystems around the world. By analysing the global warming patterns of these last four decades, this research study sheds light on where these patterns are coming from, how they are developing, and what are their impacts. This study is conducted through grey literature and analysis of the recorded global warming data publicly available by the NASA-GISS data centre for global temperature. This brief-but comprehensive-analysis helps us to have a better understanding of what comes next for global warming impacts, and how we should ultimately react. The study contributes to the field by discovering three key points analysed based on available data and literature on recorded global temperature, including: differences between north and south hemispheres, specific patterns due to ocean surface temperature increase, and recent impacts on particular regions. The study concludes with the importance of global scale analysis to have a more realistic understanding of the global warming patterns and their impacts on all living habitats.
\end{abstract}

\section{Keywords}

Global Warming, Climate Change, Global Warming Patterns, Atmospheric Temperature, Ocean Surface Temperature, Global Warming Impacts 


\section{Introduction}

Global warming is one of the primary effects of climate change [1] [2]. The existing scholarly studies prove the gradual increase since the mid-19th century [3] [4] [5] [6] [7]. The regional warming studies also indicate the increasing temperature in particular locations and larger scales that include both natural and built habitats [8] [9] [10] [11]. Hence, many context-specific studies have recorded significant impacts on productivity [12], frequency and intensity of natural disasters [2] [13] [14] [15], the reoccurrence and severity of natural disasters [16], surface warming [17], water shortage [18] [19], societal health [20], etc. By far, global warming has the highest climate impact on all living habitats [2] [21]. Global temperature data shows the average mean of Temperature Anomaly (TA) has remained positive since 1977 (Figure 1 and Table 1). However, the impacts are not positive by any means. It rather suggests while global warming fluctuates in these four decades, the average TA has never gone below $0.00^{\circ} \mathrm{C}$ [22] [23] [24], proving that global warming is not only faster than ever expected but is also progressive with no signs of conversions. It is alarming that since 2015, all TA figures are at the highest level ever and with 2016 and 2019 as the hottest and second hottest years on record (so far). Undoubtedly, this pattern, if continuing, will have a severe impact on ecology and human societies across the globe.

By assessing the publicly-available global temperature data, this study provides a comprehensive analysis of global warming patterns. This study focuses mostly on the period from 1977 onwards (due to the reason mentioned above), as it can be considered a turning point in our contemporary climatic conditions. This study portrays three key points: 1) difference in global warming patterns between north and south hemispheres, and reasons behind it; 2) correlation between global warming and increasing ocean surface temperature; and 3) global warming patterns and impacts on particular regions. With novel findings, this paper contributes to the studies on climate change and particularly global warming patterns. It is of great importance to comprehensively understand global warming patterns and its impacts at multiple scales, of which three scales of global, sub-regional, and regional are addressed here.

\section{State of the Art and Research Methods}

This study aims to shed light on three key areas in global warming patterns, especially those that are emerging in recent decades (since the late 1970s in particular). The patterns that are studied here are seen to be fluctuating in earlier decades, from the 1920s to the mid-1970s. However, as the TA has remained positive since 1977, we see minimal fluctuation and in fact, increasing global warming. Some of these have formed into recent global patterns that are important to study. The continuing patterns are worrying and they require scientific analysis and data-based analysis at multiple levels. In this study, we use the available data on recorded global temperature as well as grey literature that suggests global warming patterns in specific regions-hence, our approach here is data-based, 


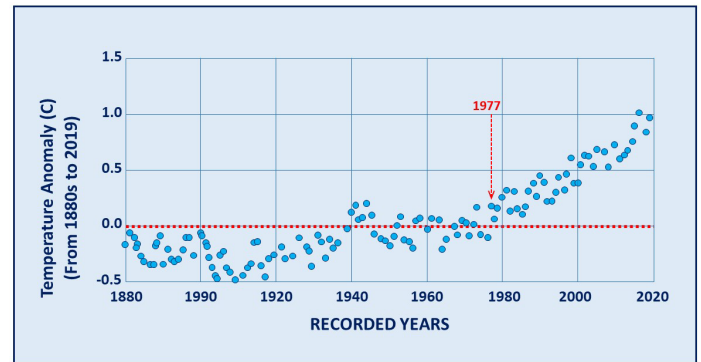

Figure 1. The records of Temperature Anomaly (TA) from 1880s to 2019 (Source adapted by the author from the Global Climate Change Data, on vital signs of the planet, global temperature section, made publicly available by NASA for the records from 1884 to 2019 so far).

Table 1. Land-Ocean Temperature Index (C), adapted from publicly available data from NASA-GISS, which shows positive TA figures from 1940 to 1945, 1952-53, 1957-59, 1962-63, 1969-70, 1972-73, and 1977-2019. The longest period of positive TA figures is since 1977, which has lasted to date. Extracted data below is from 1974, showing the negative figures until 1976 and remained positive since 1977 (Legend: yellow highlight represent the pre-1977 time with negative TA figures; red highlights represent the highest TA figures since 2015; and purple highlight represents the hottest year recorded so far, which is 2016 and with the highest TA figure).

\begin{tabular}{|c|c|c|c|c|c|}
\hline YEAR & No Smoothing & Lowess (5) & YEAR & No Smoothing & Lowess (5) \\
\hline 1974 & -0.07 & 0.00 & 1997 & 0.47 & 0.43 \\
\hline 1975 & -0.01 & 0.02 & 1998 & 0.61 & 0.45 \\
\hline 1976 & -0.10 & 0.04 & 1999 & 0.39 & 0.48 \\
\hline 1977 & 0.18 & 0.07 & 2000 & 0.39 & 0.50 \\
\hline 1978 & 0.07 & 0.12 & 2001 & 0.54 & 0.53 \\
\hline 1979 & 0.16 & 0.16 & 2002 & 0.63 & 0.55 \\
\hline 1980 & 0.26 & 0.20 & 2003 & 0.62 & 0.59 \\
\hline 1981 & 0.32 & 0.21 & 2004 & 0.54 & 0.61 \\
\hline 1982 & 0.14 & 0.21 & 2005 & 0.68 & 0.62 \\
\hline 1983 & 0.31 & 0.21 & 2006 & 0.64 & 0.63 \\
\hline 1984 & 0.15 & 0.21 & 2007 & 0.66 & 0.63 \\
\hline 1985 & 0.11 & 0.22 & 2008 & 0.54 & 0.64 \\
\hline 1986 & 0.18 & 0.24 & 2009 & 0.66 & 0.64 \\
\hline 1987 & 0.32 & 0.27 & 2010 & 0.72 & 0.65 \\
\hline 1988 & 0.38 & 0.30 & 2011 & 0.61 & 0.66 \\
\hline 1989 & 0.27 & 0.33 & 2012 & 0.64 & 0.70 \\
\hline 1990 & 0.45 & 0.33 & 2013 & 0.68 & 0.74 \\
\hline 1991 & 0.40 & 0.33 & 2014 & 0.75 & 0.78 \\
\hline 1992 & 0.22 & 0.33 & 2015 & 0.90 & 0.83 \\
\hline 1993 & 0.23 & 0.33 & 2016 & 1.02 & 0.87 \\
\hline 1994 & 0.32 & 0.34 & 2017 & 0.92 & 0.91 \\
\hline 1995 & 0.45 & 0.37 & 2018 & 0.85 & 0.95 \\
\hline 1996 & 0.33 & 0.40 & 2019 & 0.98 & 0.98 \\
\hline
\end{tabular}


which is valid for evaluation of the patterns and identifying the impacts at the global and regional levels.

The study is conducted in three parts. First, to identify the main differences between the north and south hemispheres. This is assessed based on the analysis of global warming differences in specific regions and using the available global maps that could address the differences. Second, we highlight specific patterns due to ocean surface temperature increase. This analysis benefits from the extensive literature on the topic as well as maps and temperature studies of ocean temperature data (see Table 1). And third, the study assesses recent impacts on particular regions, exploring maps on temperature variation as well as two simultaneous year-by-year and five-yearly analyses of shifting conditions in specific regions at the global level. In this part, we precisely highlight key examples that are more evident than those that are yet to be defined and/or scientifically assessed. All three are conducted based on the combined analysis of grey literature, data analysis on global temperature, and assessment of maps for specific emerging patterns. The following section provides the details of this evaluation study.

\section{Assessing Global Warming at the Global Level}

Recent climate models suggest accelerated warming and predict global warming that are expected to rise rapidly. The current climate modeling studies suggest $1.5^{\circ} \mathrm{C}$ warming increase is likely to occur in 2030 [25], which is a decade earlier than the original IPCC's original projection of 2040 [26]. This suggests a major shift in increasing global warming that has accelerated in recent decades, and in particular in recent years. The existing climate modeling studies propose options for rapid response and adaptation strategies [25], and little thoughts are given to mitigating strategies that are harder to implement and achieve. This is realised as a major gap in responding to global warming impacts [2], as we continuously deal with minimised political determination and concerns that exist around decelerating the global economic growth. More importantly, existing research lacks knowledge on global warming patterns and the impacts it currently has and will have on the societies around the globe. But why is it important to assess global warming patterns? The answer is to reveal a better and bigger picture of our contemporary climatic situation, particularly at the larger scales, and before suggesting solutions that may not be so effective down the line.

Hence, the following three key points indicate that global warming patterns are already shaped or shaping since 1977, and their impacts will continue to be more drastic than what we estimate.

\subsection{Global Warming Patterns in North and South Hemispheres}

Comparatively, the Northern hemisphere is warmer down the south, mainly due to more land surfaces, more built areas, more population density, as well as higher production and consumption patterns. The relatively large body of An- 
tarctica, in comparison to the Arctic polar region, also plays a major part in keeping the southern water bodies cooler than the north (Figure 2).

Unexpectedly, the global scale data does not indicate a by-default higher temperature in higher density areas while it is proven that heat island effects are often more significant in those populated and dense built environments. For instance, Mongolia, a country with the lowest population density, currently suffers from rapid global warming effects. This is similar to other less populated regions of Canada, Siberia, Central Asia, and the Middle East. Therefore, global warming cannot be assessed at a country-level, but at a sub-regional or even continental scale. This proves the fact that climate issues do not take into consideration the physical boundaries of the built environments, cities, and populated regions. While city-level and regional-level initiatives to combat climate change impacts are essential, we require more of larger scale plans and strategies to speed up climate change mitigation [2] [27] [28] [29]. The larger scale can be from national-level (only for larger countries) and sub-regional levels to a larger scale of continental and even with global strategies.

\subsection{Correlation between Global Warming and Increasing Ocean Surface Temperature}

The relationship between ocean temperature and global warming are studied

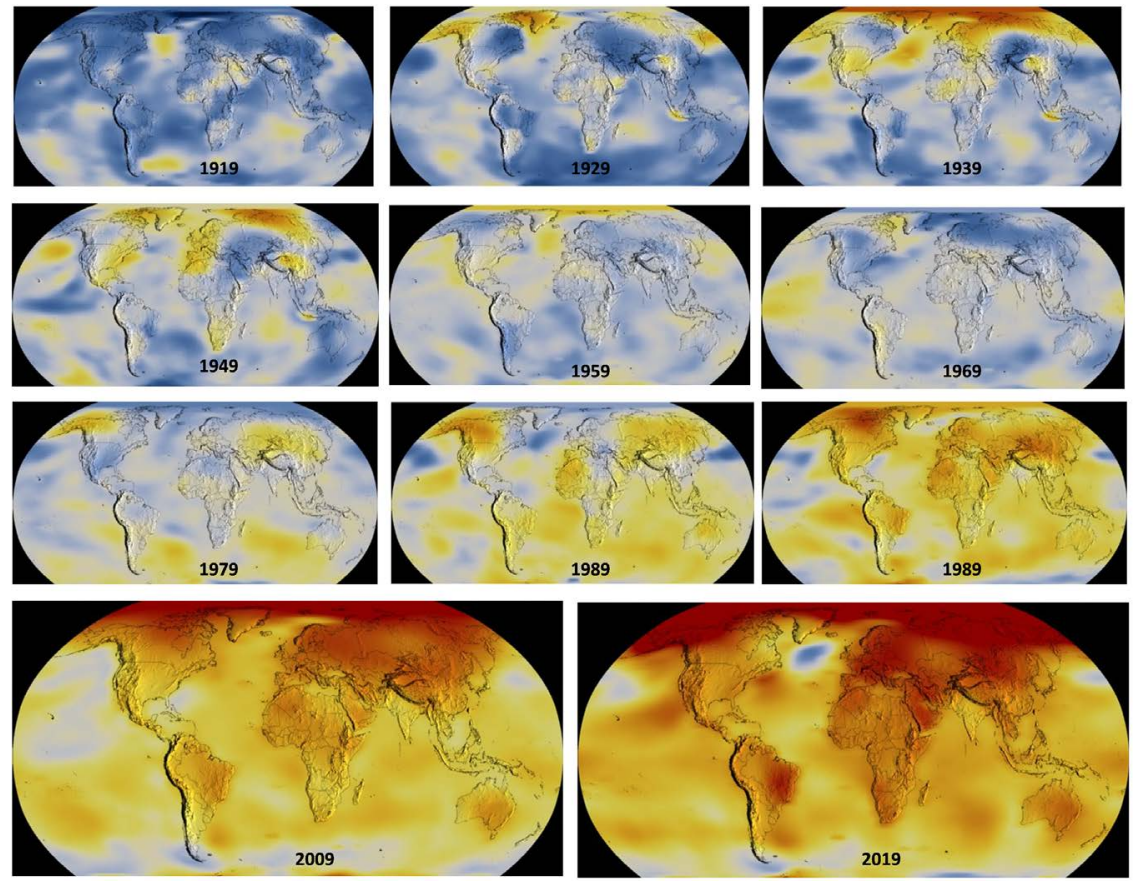

Figure 2. Global maps of growing global warming that signify the major differences between the north and south hemispheres. The maps of 100 years, shown here in every 10 years, highlight the increasing global warming that usually intensifies in the north hemisphere particularly to be seen in above examples largely in the 1930s and 1940s and then from 1980son wards (Source adapted by the author from the Global Climate Change Data, on vital signs of the planet, global temperature section, made publicly available by NASA for the records from 1884 to 2019 so far). 
from multiple perspectives that suggest the multiplicity of heat energy accumulation, heat distribution in the ocean areas, global climate-ocean ecosystem interactions, ocean ecosystem fluctuation, and solar activity effects [30]. Despite the fact that global data indicates the South Pacific Ocean area remains cooler [24], it is one of the regions hit with rapid warming conditions [31] [32]. This indicates we still have not seen the worst climatic conditions of this region, but the current trends indicate the situation will potentially worsen in the coming years. On the 6th of February 2020, Antarctica's highest temperature was recorded at $18.3^{\circ} \mathrm{C}, 0.8^{\circ} \mathrm{C}$ higher than its previous highest record in 2015 . Soon after, another this record was broken with an unexpectedly high temperature of $20.75^{\circ} \mathrm{C}$, worryingly much higher than the earlier record (both recorded and confirmed in February 2020). Also, other records suggest temperatures are constantly warming, which impacts the amount of ice lost annually from the Antarctic ice sheet by at least six-fold in the last four decades [33]. A similar pattern is also detected in the South Atlantic Ocean, particularly in the area between Atlantic Ocean and South and Pacific oceans, and consistently between the sub-region of southern Chile, Southern Argentina, and the Falkland Islands (Figure 3).

Since 2012, there is a changing pattern that a sub-region of North Atlantic Ocean started cooling down, affecting a more severe winter climate in Europe and North America. This is despite some signs of warming and temperature fluctuation in several regions [15] [34] [35] [36] [37]. The sub-regional cooling

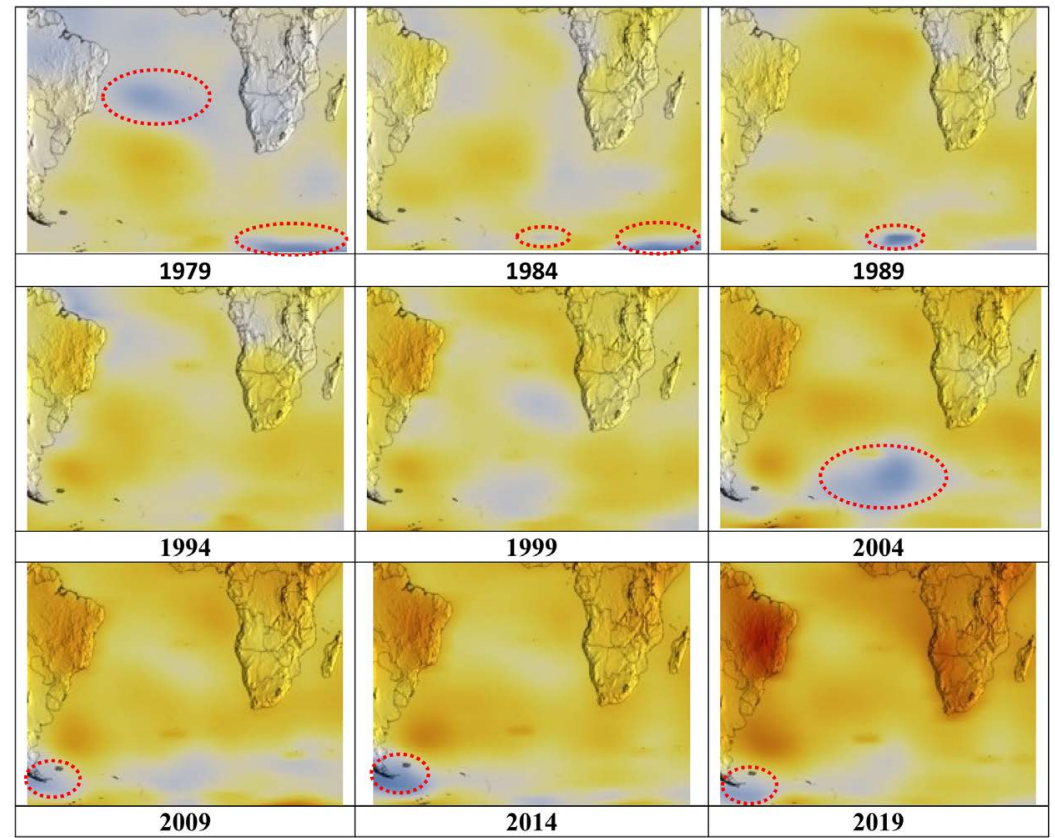

Figure 3. Demonstration of temperature changes and global warming over the South Atlantic Ocean, highlighting in particular the reduction of cooler zones/regions from larger areas in 1970s, to reduced areas and their disappearance before the new millennium, and now a very concentrated in one particular zone in the last 15 years or so (Source adapted by the author from the Global Climate Change Data, on vital signs of the planet, global temperature section, made publicly available by NASA). 
impact is sudden and severe with colder temperatures in those regions. This abrupt cooling is also thought to be a potential reoccurrence of the region's rapid cooling previously experienced in the 1970s [38]. There are also some earlier signs of temperature decline from 2005 [39]. Based on the assessment of current temperature changes in the North Pacific Ocean, there is a likelihood of a similar pattern in the coming years. However, it is still very early to conclude as the patterns are not yet emerged but are showing signs of development (Figure 4).

In recent decades, the South Ocean remains constantly cool, apart from the years 1991, 1997, 2005, and 2006. However, a sub-region between South Africa and the South American sub-continent has experienced constant global warming since 1971, with some earlier signs in 1970 and an earlier shift in temperature patterns in the mid-1960s (see Figure 3). While there are signs of slight improvements in the late 1990s and early 2000s, the areas nearer to South Africa and coastal areas of Brazil and Argentina are not improving at all; a pattern that appears emerging first in the South American side in 1973 and later around the South African region in 1986.

While there is (still) no sign of coherent pattern in the South Ocean, there are signs of significant temperature increase in the Arctic Ocean [11] [40] [41] [42] [43] [44], some emerged in the earlier period of 1907-1917, and then started to gradually increase since 1920 . With some improvement in the 1960s and early 1970s, the average temperature of the Arctic Ocean has started increasing at a faster pace and at a larger scale, since the late 1970s. This pattern was first emerging over Northern Canada and Alaska in 1979 (with earlier signs of gradual increase in 1977) and was later detected in a similar pattern over Siberia in

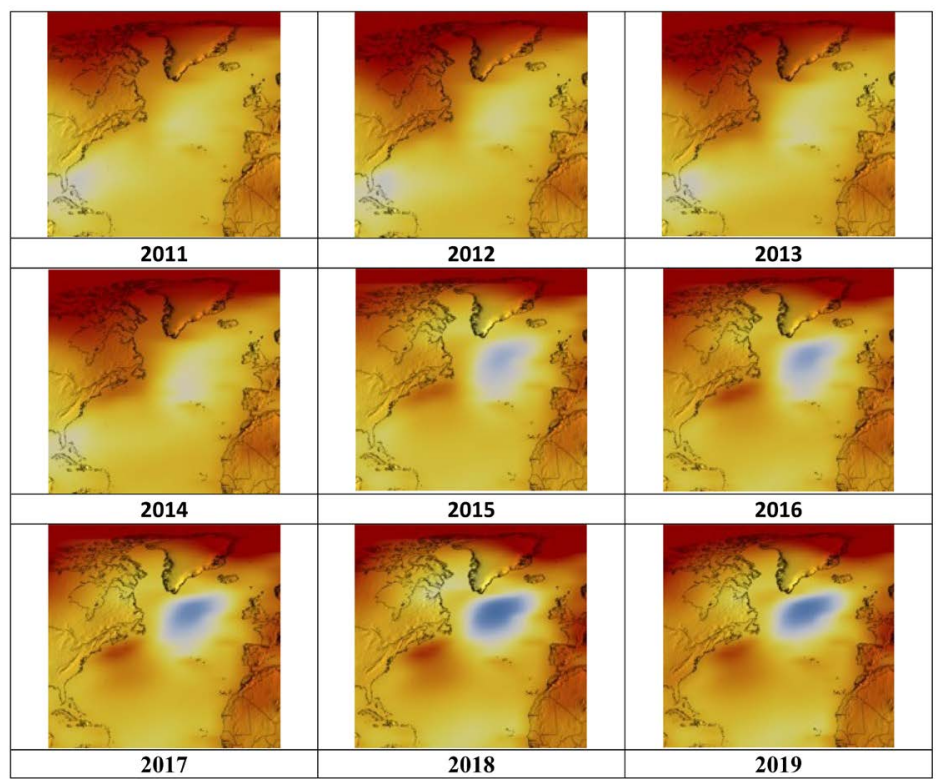

Figure 4. Recent changing patterns over the North Atlantic Ocean and the recent cooling effect in this region (Source adapted by the author from the Global Climate Change Data, on vital signs of the planet, global temperature section, made publicly available by NASA). 
1984. With some minor fluctuation, the situation in the Arctic Ocean has continued worsening since 1991 (with earlier signs from 1988-1990). The temperature increase between 1997 and 2002 becomes more evident in a much faster pace, and expands in coverage area since 2003; shifting to the alarming situation in 2012 (with a slight drop in 2013), and then 2014 onwards.

Other studies have already covered global impacts of the Indian Ocean warming [45], where TAs are assessed and simulated to prove how this specific warming pattern can "strengthen the Atlantic meridional overturning circulation". There are similar larger scale impacts from the North Atlantic Ocean and its impacts on the Pacific/North America climate variability as well as the North Pacific Ocean [46].

\subsection{Global Warming Patterns and Impacts on Particular Regions}

Existing scientific research studies, mostly assess specific global warming issues and various climatic impacts of enhanced equatorial warming [47], increasing global dryness [48] mainly due to $\mathrm{CO}_{2}$ warming [49] [50] [51], cyclone intensity migration, shifting tropical cyclone translation speed, etc.

It is evidenced that there are regular El Niño and La Niña events [52] and particularly in the Equatorial Pacific region. In recent years, these events had more impacts on both Central/South America and Australasia [24]. For instance, one of El Niño's impacts, as a result of changes in warm and cold water movements, is more rainfall on one side (e.g. in Peru) and drought in the other (e.g. in Australia and Indonesia). With the steady increase of surface temperature in the Equatorial Pacific, particularly since 2003, we see an increase in both frequency and intensity of cyclones and related natural disasters in the affected regions, particularly in the Philippines and North-Eastern part of Indonesia. In more recent years, and particularly since 2015, this has expanded in four directions covering East Asia, North Australia, South America, and Central America to part of North America (mainly Mexico and the State of California in the US) (Figure 5) [24]. The sudden shift in 2015 partly explains why 2016 was the hottest year recorded so far.

Despite the fluctuation in temperature figures, it is evident that there are signs of global warming patterns, that especially affect certain and less fortunate regions of the world. For instance, since 1997, there is a more steady temperature increase, affecting in particular much of Europe, North America, the Middle East, Central Asia, and North to North-West Africa. The main impact in these regions is substantial changes in rainfall patterns resulted in both alarming drought conditions and an increase in flooding events. A similar pattern is also seen in the Northern parts of Brazil and Australia, both with large areas of natural habitats. The average surface temperature increase in Europe has become alarming since 2014, which has resulted in longer and warmer summer periods. The extremely dry summer of 2018 was one of the alarming examples in recent years. 


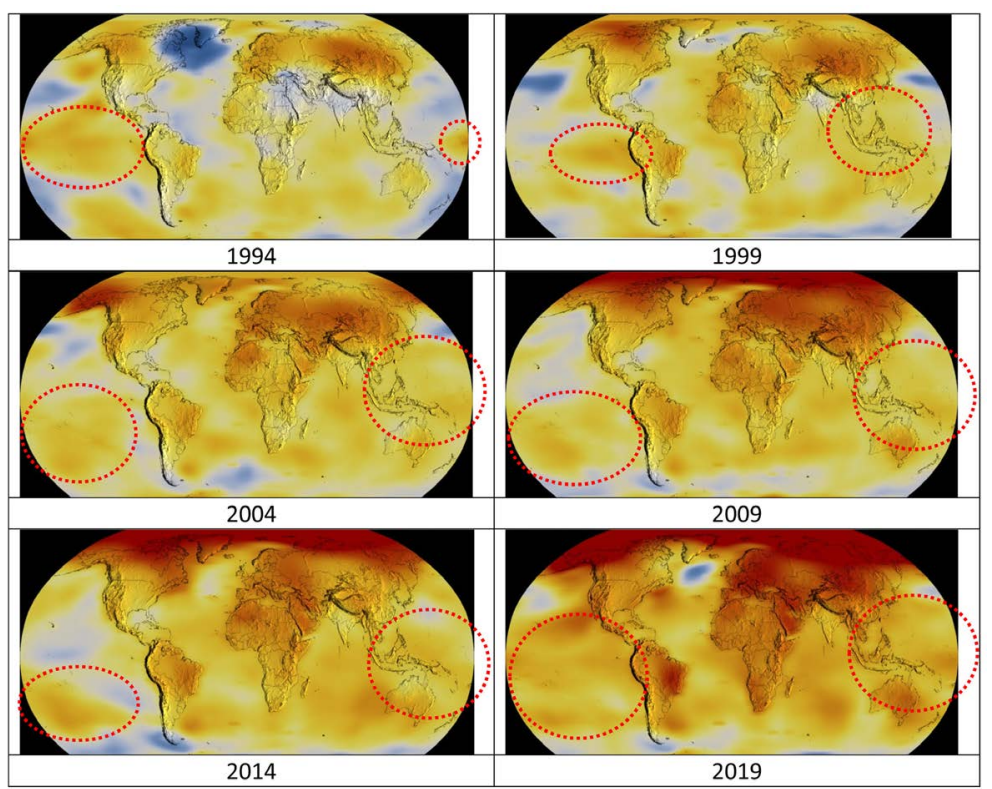

Figure 5. Recent changing patterns over Pacific Ocean, and the enlarging size of warming areas, towards a major recent shift that covers four arras of East Asia, North Australia, South America, and Central America to part of North America. The change in between 2014 and 2019 is significant, showing a growing global warming at a larger scale from 2015 onwards (Source adapted by the author from the Global Climate Change Data, on vital signs of the planet, global temperature section, made publicly available by NASA).

\section{Conclusions}

While we already know the earth as a whole is warming, it is important to identify and analyse some of the global warming patterns and impacts. This study has done this by providing new knowledge in the field of climate change. The findings are extracted from larger scale analysis, and contemporary period of 1977 onwards. Since then, the recorded years of higher temperatures show a direct correlation with warming ocean surface temperature. This study offers the first analysis of global warming patterns at the global level, identifying some of the developing and emerging global warming patterns. The novel findings of this study will support future research on global warming from both perspectives of context-specific and global-scale analyses.

This study discovers three key points associated with global warming patterns and their drastic impacts on particular areas. It questions existing research that only studies small scale or adaptation measures, and instead adds knowledge to existing research with more generic-but primary-findings. Finally, the study concludes that it is only at the global scale, that we can detect, assess, and understand global warming patterns. The impacts are at a relatively smaller scale of sub-regional, but show adverse results in different parts of the globe, particularly with a major difference between northern and southern hemispheres. The results here prove to be alarming, and with the continuing trends, the impacts will further increase, will emanate earlier, and will be more severe than previously predicted. 


\section{Funding}

This research was supported by National Natural Science Foundation of China (NSFC) for two project numbers 71850410544 (2019) and 71950410760 (2020-2021), both led by the author.

\section{Availability of Data and Material}

Primary data is available openly as a public source. The author would like to thank NASA-GISS for the available data on global temperature that are used primarily for the assessment of global warming patterns.

\section{Code Availability}

Not applicable.

\section{Conflicts of Interest}

The author declares no conflicts of interest regarding the publication of this paper.

\section{References}

[1] IPCC (Intergovernmental Panel on Climate Change) (2007) Climate Change. The Physical Science Basis. In: Solomon, S., Qin, D., Manning, M., Chen, Z., Marquis, M., Averyt, K.B., et al., Eds., Contribution of Working Group I to the 4th Assessment Report of the Intergovernmental Panel on Climate Change, Cambridge University Press, New York, 747-848.

[2] Cheshmehzangi, A. and Dawodu, A. (2019) Sustainable Urban Development in the Age of Climate Change-People: The Cure or Curse. Palgrave Macmillan, Singapore and Germany.

[3] Andronova, N.G. and Schlesinger, M.E. (2000) Causes of Temperature Changes during the 19th and 20th Centuries. Geophysical Research Letters, 27, 2137-2140. https://doi.org/10.1029/2000GL006109

[4] Ring, M.J. Lindner, D. Cross, E.F. and Schlesinger, M.E. (2012) Causes of the Global Warming Observed since the 19th Century. Atmospheric and Climate Sciences, 2, 401-415. https://doi.org/10.4236/acs.2012.24035

[5] Intergovernmental Panel on Climate Change (IPCC) (2013) Summary for Policymakers. In: Stocker, T.F., Qin, D., Plattner, G.-K., Tignor, M., Allen, S.K., Boschung, J., Nauels, A., Xia, Y., Bex, V. and Midgley, P.M., Eds., Climate Change, the Physical Science Basis. Contribution of Working Group I to the Fifth Assessment Report of the Intergovernmental Panel on Climate Change, Cambridge University Press, Cambridge, UK and New York, USA, 3-29.

[6] Zhao, X.H. and Feng, X.S. (2014) Periodicities of Solar Activity and the Surface Temperature Variation of the Earth and Their Correlations. Chinese Scientific Bulletin, 59, 1284-1292. https://doi.org/10.1360/972013-1089

[7] Ogurtsov, M., Lindholm, M. and Jalkanen, R. (2017) On the Possible Contribution of Natural Climatic Fluctuations to the Global Warming of the Last 135 Years. At mospheric and Climate Sciences, 7, 256-262. https://doi.org/10.4236/acs.2017.73018

[8] Barnett, T.P., Adam, J.C. and Lettenmaier, D.P. (2005) Potential Impacts of a Warming Climate on Water Availability in Snow-Dominated Regions. Nature, 438, 
303-309. https://doi.org/10.1038/nature04141

[9] Rao, V., Franchito, S., Gerólamo, R., Giarolla, E., Ramakrishna, S., Rao, B. and Naidu, C. (2016) Himalayan Warming and Climate Change in India. American Journal of Climate Change, 5, 558-574. https://doi.org/10.4236/ajcc.2016.54038

[10] Wang, B., Bao, Q., Hoskins, B., Wu, G. and Liu, Y. (2008) Tibetan Plateau Warming and Precipitation Changes in East Asia. Geophysical Research Letters, 35, L14702. https://doi.org/10.1029/2008GL034330

[11] Fazel-Rastgar, F. (2019) Hudson Bay Climate Change and Local Winter Wind Circulation. American Journal of Climate Change, 8, 544-560.

https://doi.org/10.4236/ajcc.2019.84029

[12] Justino, F., Oliveira, E., Rodrigues, R., Gonçalves, P., Souza, P., Stordal, F., Marengo, J., Silva, T., Delgado, R., Lindemann, D. and Costa, L. (2013) Mean and Interannual Variability of Maize and Soybean in Brazil under Global Warming Conditions. American Journal of Climate Change, 2, 237-253. https://doi.org/10.4236/ajcc.2013.24024

[13] Webster, P.J., Holland, G.J., Curry, A. and Chang, H.R. (2005) Changes in Tropical Cyclone Number, Duration, and Intensity in a Warming Environment. Science, 309, 1844-1846. https://doi.org/10.1126/science.1116448

[14] Trenberth, K. (2005) Uncertainty in Hurricanes and Global Warming. Science, 308, 1753-1754. https://doi.org/10.1126/science.1112551

[15] McCloskey, T., Bianchette, T. and Liu, K. (2013) Track Patterns of Landfalling and Coastal Tropical Cyclones in the Atlantic Basin, Their Relationship with the North Atlantic Oscillation (NAO), and the Potential Effect of Global Warming. American Journal of Climate Change, 2, 12-22. https://doi.org/10.4236/ajcc.2013.23A002

[16] Praveen, D. and Ramachandran, A. (2015) Projected Warming and Occurrence of Meteorological Droughts-Insights from the Coasts of South India. American Journal of Climate Change, 4, 173-179. https://doi.org/10.4236/ajcc.2015.42013

[17] Hornbach, M., Richards, M., Blackwell, D., Mauroner, C. and Brokaw, C. (2016) 40 Years of Surface Warming in the Northern US Rocky Mountains: Implications for Snowpack Retreat. American Journal of Climate Change, 5, 275-295. https://doi.org/10.4236/ajcc.2016.52023

[18] Kehl, J. (2018) The Great Lapse: Climate Change, Water Resources and Economic Risks in the Great Lakes. Journal of Water Resource and Protection, 10, 1106-1114. https://doi.org/10.4236/jwarp.2018.1011065

[19] Mote, P.W., Hamlet, A.F., Clark, M.P. and Lettenmaier, D.P. (2005) Declining Mountain Snowpack in Western North America. Bulletin of the American Meteorological Society, 86, 39-49. https://doi.org/10.1175/BAMS-86-1-39

[20] Cheshmehzangi, A. and Dawodu, A. (2020) Passive Cooling Energy Systems: Holistic SWOT Analyses for Achieving Urban Sustainability. International Journal of Sustainable Energy, 39, 1-21. https://doi.org/10.1080/14786451.2020.1763348

[21] Malcolm, J.R., Liu, C., Miller, L.B., Allutt, T. and Hansen, L. (2002) Habitats at Risk: Global Warming and Species Loss in Globally Significant Terrestrial Ecosystems. Washington DC; University of North Texas Libraries, UNT Digital Library. https://digital.library.unt.edu/ark:/67531/metadc226787/m1/33/ https://digital.library.unt.edu

[22] Hansen, J., Ruedy, R., Sato, M. and Lo, K. (2002) Global Warming Continues. Science, 295, 275. https://doi.org/10.1126/science.295.5553.275c

[23] Hafez, Y. and Almazroui, M. (2014) Recent Study of Anomaly of Global Annual 
Geopotential Height and Global Warming. Atmospheric and Climate Sciences, 4, 347-357. https://doi.org/10.4236/acs.2014.43035

[24] NASA's Goddard Institute for Space Studies (GISS) (2020) Global Temperature.

[25] Xu, Y., Ramanathan, V. and Victor, D.G. (2018) Global Warming will Happen Faster than We Think. Nature, 564, 30-32.

https://doi.org/10.1038/d41586-018-07586-5

[26] Intergovernmental Panel on Climate Change (IPCC) (2014) Fifth Assessment Report. https://www.ipcc.ch/assessment-report/ar5/

[27] Massawe, A. (2012) Global Warming Control to Mitigate Climate Change. Engineering, 4, 252-255. https://doi.org/10.4236/eng.2012.45033

[28] Cheshmehzangi, A. and Butters, C., Eds. (2018) Designing Cooler Cities: Energy, Cooling and Urban Form: The Asian Perspective. Palgrave Macmillan, Singapore.

[29] Creutzig, F. (2019) The Mitigation Trinity: Coordinating Policies to Escalate Climate Mitigation. One Earth, 1, 76-85. https://doi.org/10.1016/j.oneear.2019.08.007

[30] Navrotsky, V. (2013) Effects of the World's Oceans on Global Climate Change. American Journal of Climate Change, 2,183-190.

https://doi.org/10.4236/ajcc.2013.23018

[31] Cannon, A., Lalor, P., Sriharan, S., Fan, C. and Ozbay, G. (2014) A Case Study on Climate Change Response and Adaptation: Fictional Aysese Islands in the South Pacific. American Journal of Climate Change, 3, 455-473. https://doi.org/10.4236/ajcc.2014.35040

[32] Yu, L., Zhang, Z., Zhou, M., Zhong, S., Lenschow, D., Li, B., Wang, X., Li, S., Wu, H. and Sun, B. (2012) Trends in Latent and Sensible Heat Fluxes over the Southern Ocean. Atmospheric and Climate Sciences, 2, 159-173. https://doi.org/10.4236/acs.2012.22017

[33] World Meteorological Organization (WMO) (2020) Report by Claire Nullis. https://news.un.org/fr/story/2020/02/1061402

[34] Magnus, J.R., Melenberg, B. and Muris, C. (2011) Global Warming and Local Dimming: The Statistical Evidence. Journal of the American Statistical Association, 106, 452-468. https://doi.org/10.1198/jasa.2011.ap09508

[35] Martín, J.L., Bethencourt, J. and Cuevas-Agulló, E. (2012) Assessment of Global Warming on the Island of Tenerife, Canary Islands (Spain). Trends in Minimum, Maximum and Mean Temperatures Since 1944. Climatic Change, 114, 343-355. https://doi.org/10.1007/s10584-012-0407-7

[36] Mazzarella, A. and Scafetta, N. (2012) Evidences for a Quasi 60-Year North Atlantic Oscillation since 1700 and Its Meaning for Global Climatic Change. Theoretical and Applied Climatology, 107, 599-609. https://doi.org/10.1007/s00704-011-0499-4

[37] Luque, A., Martín, J., Dorta, P. and Mayer, P. (2014) Temperature Trends on Gran Canaria (Canary Islands). An Example of Global Warming over the Subtropical Northeastern Atlantic. Atmospheric and Climate Sciences, 4, 20-28. https://doi.org/10.4236/acs.2014.41003

[38] Sgubin, G., Swingedouw, D., Drijfhout, S., Mary, Y. and Bennabi, A. (2017) Abrupt Cooling over the North Atlantic in Modern Climate Models. Nature Communications, 8, Article No. 14375. https://doi.org/10.1038/ncomms14375

[39] Mazzarella, A. (2013) Time-Integrated North Atlantic Oscillation as a Proxy for Climatic Change. Natural Science, 5, 149-155. https://doi.org/10.4236/ns.2013.51A023

[40] Polyakov, I.V., Alexeev, V.A., Ashik, I.M., Bacon, S., Beszczynska-Möller, A., Car- 
mack, E.C., Woodgate, R., et al. (2011) Fate of Early 2000s Arctic Warm Water Pulse. Bulletin of the American Meteorological Society, 92, 561-566. https://doi.org/10.1175/2010BAMS2921.1

[41] Bourgain, P. and Gascard, J.C. (2012) The Atlantic and Summer Pacific Waters Variability in the Arctic Ocean from 1997 to 2008. Geophysical Research Letters, 39, L05603. https://doi.org/10.1029/2012GL051045

[42] Walsh, J.E. (2014) Intensified Warming of the Arctic: Causes and Impacts on Middle Latitudes. Global and Planetary Change, 117, 52-63. https://doi.org/10.1016/j.gloplacha.2014.03.003

[43] Döscher, R., Vihma, T. and Maksimovich, E. (2014) Recent Advances in Understanding the Arctic Climate System State and Change from a Sea Ice Perspective: A Review. Atmospheric Chemistry and Physics Discussions, 14, 13571-13600. https://doi.org/10.5194/acpd-14-10929-2014

[44] Fazel-Rastgar, F. (2020) The Evidence of Recent Canadian Arctic Climate Change: A Case Study, the Baffin Island. International Journal of Global Warming, 20, 165-185. https://doi.org/10.1504/IJGW.2020.10027062

[45] Hu, S. and Fodorov, A.V. (2019) Indian Ocean Warming can Strengthen the Atlantic Meridional Overturning Circulation. Nature Climate Change, 9, 747-751. https://doi.org/10.1038/s41558-019-0566-x

[46] Zhang, R. and Delworth, T.L. (2007) Impact of the Atlantic Multidecadal Oscillation on North Pacific Climate Variability. Geophysical Research Letters, 34, L23708. https://doi.org/10.1029/2007GL031601

[47] Zhou, W., Xie, S.P., and Yang, D. (2019) Enhanced Equatorial Warming Causes Deep-Tropical Contraction and Subtropical Monsoon Shift. Nature Climate Change, 9, 834-839. https://doi.org/10.1038/s41558-019-0603-9

[48] Scheff, J. and Frierson, D.M.W. (2012) Robust Future Precipitation Declines in CMIP5 Largely Reflect the Poleward Expansion of Model Subtropical Dry Zones. Nature Climate Change Geophysical Research Letters, 39, L18704. https://doi.org/10.1029/2012GL052910

[49] Lau, W.K.M. and Kim, K.-M. (2015) Robust Hadley Circulation Changes and Increasing Global Dryness Due to $\mathrm{CO}_{2}$ Warming from CMIP5 Model Projections. Proceedings of the National Academy of Sciences of the United States of America, 112, 3630-3635. https://doi.org/10.1073/pnas.1418682112

[50] Carr, P.H. (2013) Weather Extremes from Anthropogenic Global Warming. Natural Science, 5, 130-134. https://doi.org/10.4236/ns.2013.51A020

[51] Chilingar, G., Sorokhtin, O., Khilyuk, L. and Liu, M. (2014) Do Increasing Contents of Methane and Carbon Dioxide in the Atmosphere Cause Global Warming. Atmospheric and Climate Sciences, 4, 819-827. https://doi.org/10.4236/acs.2014.45072

[52] Douglass, D., Knox, R., Curtis, S., Giese, B. and Ray, S. (2017) Historical Phase-Locked El Niño Episodes. Atmospheric and Climate Sciences, 7, 48-64.

https://doi.org/10.4236/acs.2017.71005 